\title{
Comparison of T-piece and pressure support ventilation as spontaneous breathing trials in critically ill patients: a systematic review and meta-analysis
}

Yuting Li, Hongxiang Li and Dong Zhang*

\begin{abstract}
Background: The effect of alternative spontaneous breathing trial (SBT) techniques on extubation success and other clinically important outcomes is uncertain. A systematic review and meta-analysis was performed to clarify the preferable SBT (T-piece or pressure support ventilation [PSV]).

Methods: We searched the PubMed, Cochrane, and Embase databases for randomized controlled trials (RCTs) from inception to the 31st of July 2019. We included RCTs involving adult patients (> 18 years) who underwent at least two different SBT methods. All authors reported our primary outcome of successful extubation rate and clearly compared PS versus T-piece with clinically relevant secondary outcomes (rate of reintubation, ICU and hospital length of stay, and ICU and hospital mortality). Results were expressed as odds ratio (OR) and mean difference (MD) with accompanying 95\% confidence interval (Cl).

Results: Ten RCTs including 3165 patients were included. The results of this meta-analysis showed that there was no significant difference in the successful extubation rate between the T-piece group and PS group (odds ratio $[O R]=0.91 ; 95 \% \mathrm{Cl}, 0.78-1.07 ; P=0.27 ; P^{2}=79 \%$ ). In addition, compared with the PS group, the T-piece group showed no significant difference in the rate of reintubation (odds ratio $[\mathrm{OR}]=0.99 ; 95 \% \mathrm{Cl}, 0.78-1.26 ; P=0.95 ; P=$ $5 \%$ ), ICU mortality (odds ratio $[\mathrm{OR}]=1.22 ; 95 \% \mathrm{Cl}, 0.83-1.80 ; P=0.30 ; P^{2}=0 \%$ ), hospital mortality (odds ratio $[\mathrm{OR}]=$ $1.36 ; 95 \% \mathrm{Cl}, 0.99-1.87 ; P=0.06 ; P^{2}=19 \%$ ), ICU length of stay (mean difference $=-0.10 ; 95 \% \mathrm{Cl},-0.59$ to $0.39 ; P=$ $0.69 ; P^{2}=13 \%$ ), and hospital length of stay (mean difference $=-0.82 ; 95 \% \mathrm{Cl},-2.2$ to $0.55 ; P=0.24 ; P^{2}=0 \%$ ).
\end{abstract}

Conclusions: T-piece and PSV as SBTs are considered to have comparable predictive power of successful extubation in critically ill patients. The analysis of secondary outcomes also shows no significant difference in the rate of reintubation, ICU and hospital length of stay, and ICU and hospital mortality between the two groups. Further randomized controlled studies of SBTs are still required.

Keywords: T-piece, Pressure support ventilation, Spontaneous breathing trials, Randomized controlled trials, Systematic review, Meta-analysis

\footnotetext{
* Correspondence: zhangdong21245@sina.com

Department of Intensive Care Unit, The First Hospital of Jilin University,

Changchun, Jilin 130021, China
}

(c) The Author(s). 2020 Open Access This article is distributed under the terms of the Creative Commons Attribution 4.0 International License (http://creativecommons.org/licenses/by/4.0/), which permits unrestricted use, distribution, and reproduction in any medium, provided you give appropriate credit to the original author(s) and the source, provide a link to the Creative Commons license, and indicate if changes were made. The Creative Commons Public Domain Dedication waiver (http://creativecommons.org/publicdomain/zero/1.0/) applies to the data made available in this article, unless otherwise stated. 


\section{Key messages}

- T-piece and PSV as SBTs are considered to have comparable predictive power of successful extubation in critically ill patients.

- Further randomized controlled studies of SBTs are still required to confirm our results.

\section{Background}

Mechanical ventilation is often required in patients with critical illness, but after recovery from the acute illness, several problems can impair the successful separation of the patient from the ventilator [1]. Weaning from mechanical ventilation is one of the most important and challenging problems for most intensive care unit (ICU) patients. It is well known that weaning failure is associated with longer use of mechanical ventilation, higher infection rate, longer ICU stay, longer hospital stay, and higher mortality rate [2]. A spontaneous breathing trial (SBT) is most often performed to assess the ability of a patient to sustain spontaneous breathing when extubated [3]. The most common modes of SBT are T-piece ventilation and pressure support ventilation (PSV), last-

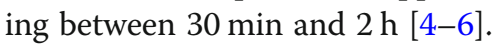

Discontinuation of mechanical ventilation should be accomplished when the patient's ability to breathe unassisted is identified. Both premature and delayed ventilator discontinuation are associated with significant morbidity. Daily spontaneous breathing trials (SBTs) are the current evidence-based standard of care in determining the time of ventilator discontinuation. When patients are ready to wean, the weaning process should be initiated with the first SBT as soon as possible. Nevertheless, about $15-30 \%$ of the patients will be re-intubated even if they are able to tolerate (or pass) the SBT [7].

A recent meta-analysis suggested that patients undergoing PS (vs T-piece) SBTs appear to be $6 \%$ more likely to be extubated successfully and, if the results of an outlier trial are excluded, 6\% more likely to pass an SBT [8]. Another meta-analysis found that PSV might be superior to $\mathrm{T}$-piece with regard to weaning success for simple-towean subjects. For the prolonged-weaning subgroup, however, T-piece was associated with a shorter weaning duration [9]. A latest large-scale multicenter randomized controlled trial found that an SBT consisting of $30 \mathrm{~min}$ of PSV, compared with $2 \mathrm{~h}$ of T-piece ventilation, led to significantly higher rates of successful extubation [10]. Moreover, the latest American Thoracic Society

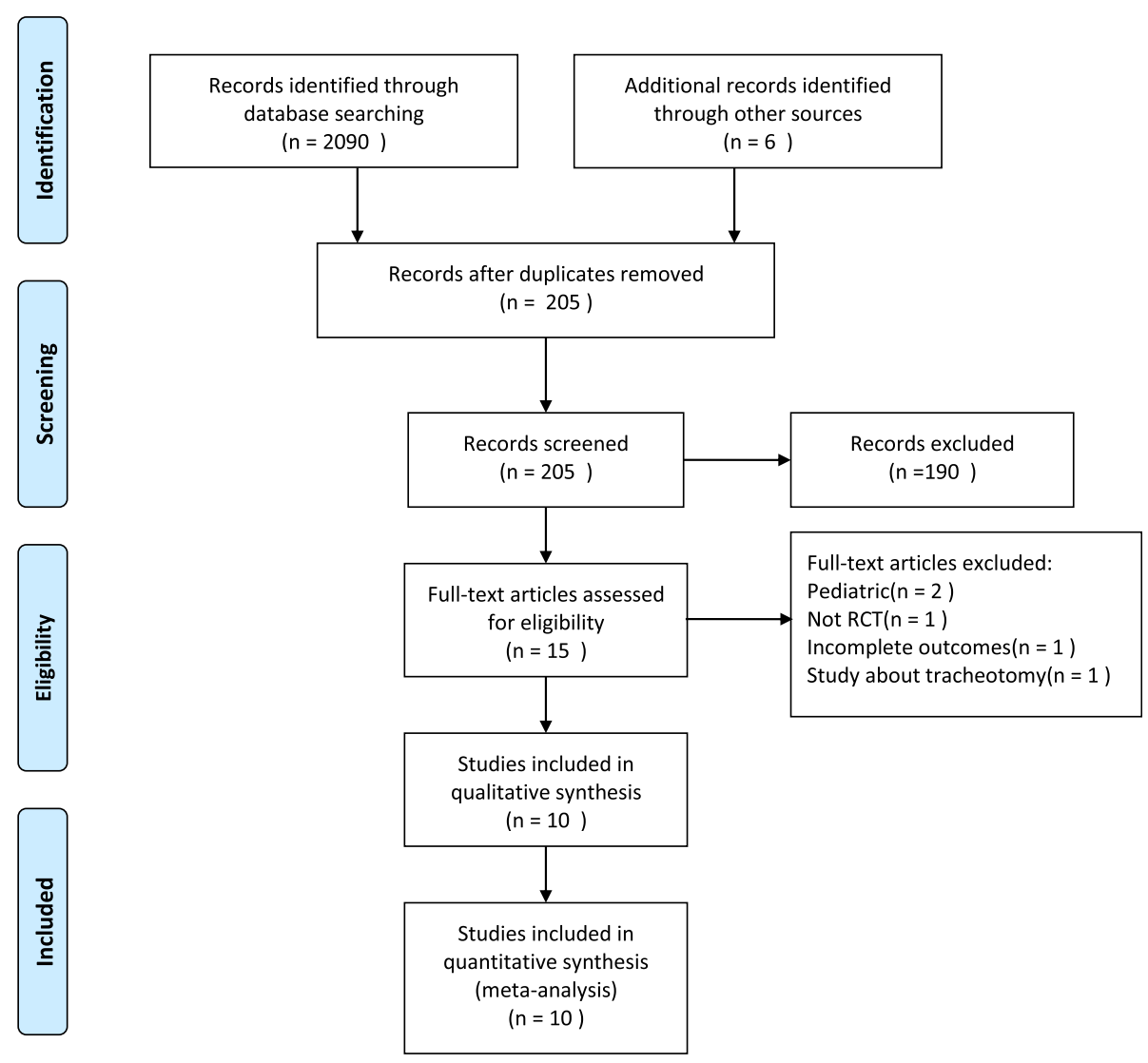

Fig. 1 Flow chart of literature selection 


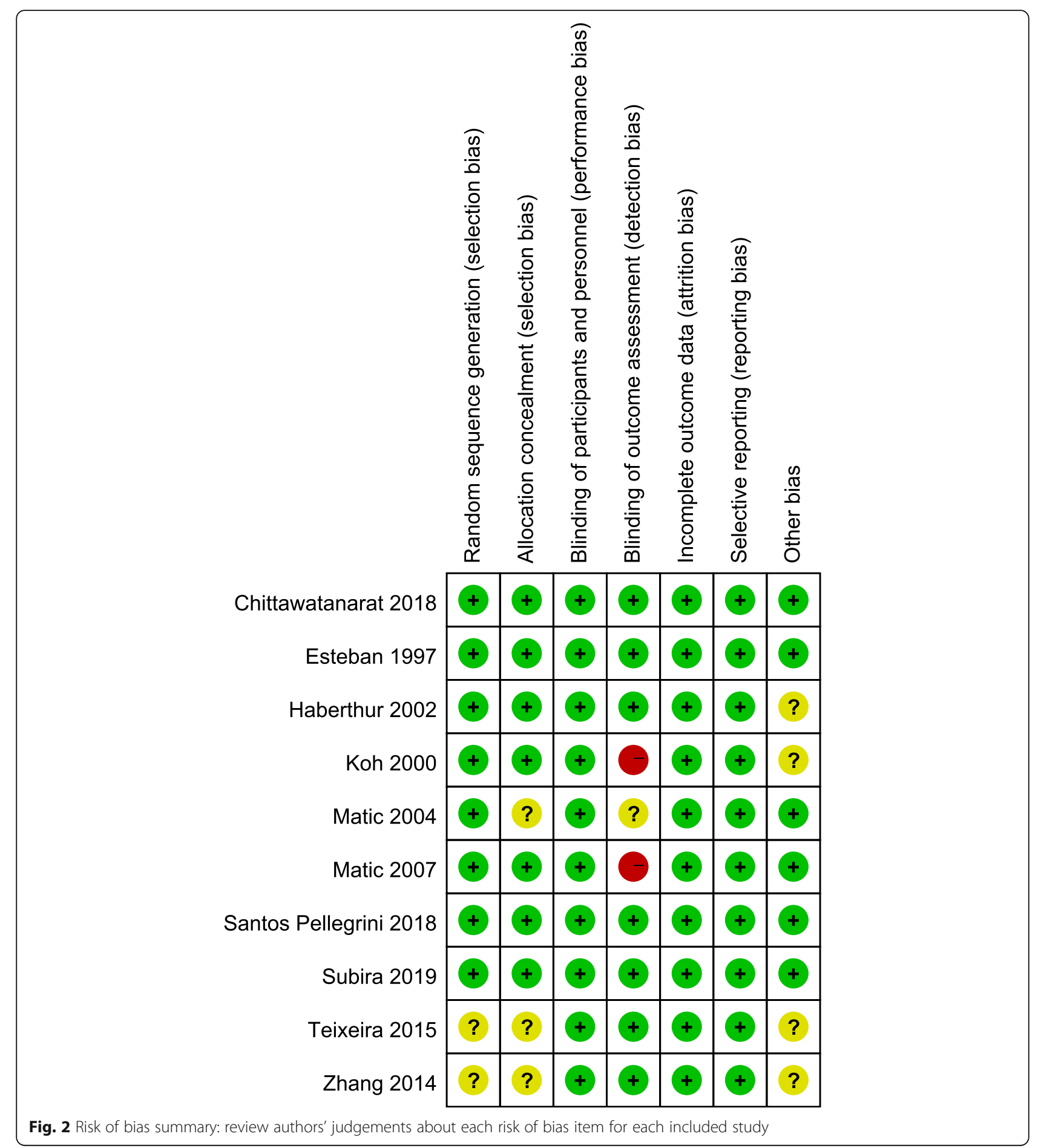

guidelines for weaning recommend PSV SBTs with moderate-quality evidence [11]. Thus, further research is needed to determine the best approach for SBTs.

In this study, we conducted a meta-analysis, which extracted results from published randomized controlled trials (RCTs) to evaluate the effectiveness and safety of two strategies, a T-piece and PSV, for weaning adult patients with respiratory failure that required mechanical ventilation, measuring extubation success and other clinically important outcomes.

\section{Methods}

This systematic review and meta-analysis is reported according to the Preferred Reporting Items for Systematic 


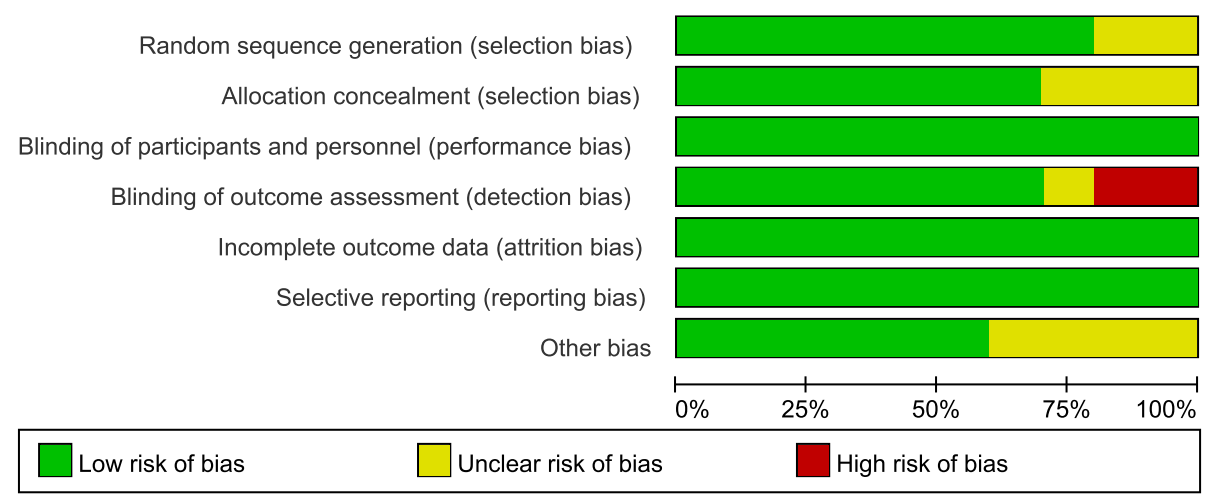

Fig. 3 Risk of bias graph: review authors' judgements about each risk of bias item presented as percentages across all included studies

Reviews and Meta-Analyses (PRISMA) guidelines [12]. Ethical approval was not necessary for this study because it was a review of the published literature.

\section{Search strategy}

We searched the PubMed, Cochrane, and Embase databases for RCTs from inception to the 31st of July 2019 using the following search terms: spontaneous breathing trial, T-piece, T-tube, pressure support ventilation, pressure support, weaning, ventilator weaning, mechanical ventilation. The search was slightly adjusted according to the requirements of the different databases. The authors' personal files and reference lists of relevant review articles were also reviewed. The flow chart of the search strategies is summarized in Fig. 1.

\section{Types of outcome measures}

The primary outcome was successful extubation rate, and successful extubation was defined as remaining free of invasive mechanical ventilation $72 \mathrm{~h}$ after the first SBT [10].

Secondary outcomes were rate of reintubation among patients who were extubated after the SBT, ICU, and hospital length of stay, and ICU and hospital mortality. Weighted means were calculated based on the number of patients in each study.

\section{Study selection}

The inclusion criteria were as follows: (1) randomized controlled trials; (2) adult patients ( $>18$ years) who underwent at least two different SBT methods; (3) all authors reported our primary outcome of successful extubation rate; (4) clearly comparing PS versus T-piece with clinically relevant secondary outcomes. We excluded nonrandomized controlled trials and studies without clear comparisons of the outcomes. In addition, we excluded studies evaluating SBT methods in patients with tracheotomy and in patients receiving noninvasive ventilation.

\section{Quality assessment}

Two reviewers (YL and HL) independently performed quality assessment using the Cochrane Collaboration's tool for assessing risk of bias [13]. The specific elements were adequacy of the methods used to minimize bias through: (1) randomization sequence (selection bias), (2)

Table 1 The basic characteristics of studies included in meta-analysis

\begin{tabular}{|c|c|c|c|c|c|c|c|}
\hline \multirow[t]{2}{*}{ Author } & \multirow[t]{2}{*}{ Year } & \multirow[t]{2}{*}{ Country } & \multirow[t]{2}{*}{ Study period } & \multirow[t]{2}{*}{ Study design } & \multicolumn{3}{|c|}{ No. of patients } \\
\hline & & & & & Total & PS & T-piece \\
\hline Ebsteban & 1997 & Spain & Oct. 1994-Jun. 1995 & Multicenter & 484 & 238 & 246 \\
\hline Koh & 2000 & Korea & May 1997-Mar. 1998 & Single center & 42 & 20 & 22 \\
\hline Haberthur & 2002 & Switzerland & Jul. 1997-Jul. 1998 & Single center & 60 & 30 & 30 \\
\hline Matic & 2004 & Croatia & Aug. 1999-Oct. 2000 & Single center & 260 & 150 & 110 \\
\hline Matic & 2007 & Croatia & Apr. 2004-Apr. 2006 & Single center & 136 & 70 & 66 \\
\hline Zhang & 2014 & China & Jan. 2007-Dec. 2007 & Single center & 208 & 93 & 115 \\
\hline Teixeira & 2015 & Brazil & Nov. 2012-Nov. 2013 & Single center & 112 & 46 & 66 \\
\hline Chittawatanarat & 2018 & Thailand & Jun. 2011-Nov. 2013 & Single center & 520 & 260 & 260 \\
\hline Santos Pellegrini & 2018 & Brazil & 2012-2016 & Multicenter & 190 & 91 & 99 \\
\hline Subira & 2019 & Spain & Jan. 2016-Apr. 2017 & Multicenter & 1153 & 575 & 578 \\
\hline
\end{tabular}


Table 2 Interventions of PS and T-piece included in the meta-analysis

\begin{tabular}{|c|c|c|}
\hline Study & PS & T-piece \\
\hline $\begin{array}{l}\text { Esteban } 1997 \\
\text { Koh } 2000 \\
\text { Haberthur } 2002 \\
\text { Matic } 2004 \\
\text { Matic } 2007\end{array}$ & $\begin{array}{l}\text { PS } 7 \mathrm{~cm} \mathrm{H}_{2} \mathrm{O} 2 \mathrm{~h} \\
\text { PS } 15 \mathrm{~cm} \mathrm{H}_{2} \mathrm{O} \text {, decrease } 3-5 \mathrm{~cm} \mathrm{H}_{2} \mathrm{O} / \mathrm{h} \\
\text { PS } 5 \mathrm{~cm} \mathrm{H}_{2} \mathrm{O} \text {, PEEP } 5 \mathrm{~cm} \mathrm{H}_{2} \mathrm{O} 2 \mathrm{~h} \\
\text { PS } 8 \mathrm{cmH}_{2} \mathrm{O} 2 \mathrm{~h} \\
\text { PS } 18 \mathrm{~cm} \mathrm{H}_{2} \mathrm{O} \text {, decrease } 2-4 \mathrm{~cm} \mathrm{H}_{2} \mathrm{O} / \text { time to } 5 \mathrm{~cm} \mathrm{H}_{2} \mathrm{O}\end{array}$ & $\begin{array}{l}\text { T-piece } 2 \mathrm{~h} \\
\text { T-piece } 1 \mathrm{~h} \\
\text { T-piece } 2 \mathrm{~h} \\
\text { T-piece } 2 \mathrm{~h} \\
\text { T-piece } 2 \mathrm{~h}\end{array}$ \\
\hline Zhang 2014 & PS $5 \mathrm{~cm} / \mathrm{H}_{2} \mathrm{O}$, PEEP $5 \mathrm{~cm} \mathrm{H} \mathrm{H}_{2} \mathrm{O}, \mathrm{FiO}_{2} 30 \% 30 \mathrm{~min}$ & T-piece $4 \mathrm{~L} / \mathrm{min} 30 \mathrm{~min}$ \\
\hline $\begin{array}{l}\text { Teixeira } 2015 \\
\text { Chittawatanarat } 2018 \\
\text { Santos Pellegrini } 2018 \\
\text { Subira } 2019\end{array}$ & $\begin{array}{l}\text { PS } 7 \mathrm{~cm} \mathrm{H} \mathrm{C}_{2} \mathrm{O} \text {, PEEP } 5-8 \mathrm{~cm} \mathrm{H} \mathrm{H}_{2} \mathrm{O} \mathrm{FiO}_{2} \leq 45 \% 30-90 \mathrm{~min} \\
\text { PS } 5-7 \mathrm{~cm} \mathrm{H}_{2} \mathrm{O} \text {, PEEP } 5 \mathrm{~cm} \mathrm{H}_{2} \mathrm{O}, \mathrm{FiO}_{2} 40 \% 120 \mathrm{~min} \\
\text { PS } 10 \mathrm{~cm} \mathrm{H}_{2} \mathrm{O} 30 \mathrm{~min} \\
\text { PS } 8 \mathrm{~cm} \mathrm{H}_{2} \mathrm{O} \text {, PEEP } 030 \mathrm{~min}\end{array}$ & $\begin{array}{l}\text { T-piece } 30-90 \mathrm{~min} \\
\text { T-piece } 10-15 \mathrm{~L} / \mathrm{min} 120 \mathrm{~min} \\
\text { T-piece } 30 \mathrm{~min} \\
\text { T-piece } 2 \mathrm{~h}\end{array}$ \\
\hline
\end{tabular}

allocation concealment (selection bias), (3) blinding of study personnel and participants (performance bias), (4) blinding of outcome assessors (performance bias), (5) complete reporting of data without arbitrarily excluded patients and with low to minimal loss to follow-up (attrition bias), (6) selective reporting bias, and (7) other sources of bias. Satisfactory performance, unclear performance, and unsatisfactory performance of each domain from the tool is denoted by green, yellow, and red colors respectively. The risk of bias summary is presented in Fig. 2; the risk of bias graph is presented in Fig. 3.

\section{Statistical analysis}

Statistical analyses were performed using Review Manager Version 5.3 (RevMan, The Cochrane Collaboration, Oxford, UK). Risk ratio (RR) with 95\% confidence intervals (CI) was calculated for dichotomous variables. As to the continuous variables, mean difference (MD) and 95\% CI was estimated as the effect result. A random-effects model was used to pool studies with significant heterogeneity, as determined by the chi-squared test $(P<0.10)$ and inconsistency index $\left(I^{2} \geq 50 \%\right)$ [14]. Some of the selected continuous variables were represented by the median (interquartile range). We calculated their mean and standard deviation according to the sample size with a calculator [15], and then performed meta-analysis. A $P$ value $<0.05$ was set as the threshold of statistical significance.

\section{Result}

\section{Study characteristics}

The search strategy identified 2090 studies, and the data were from 10 RCTs comprising 3165 patients (Table 1) [10, 16-24]. The characteristics of the included studies are shown in Table 1. A total of 10 eligible studies were published between 1997 and 2019. Among these studies, 2 studies were conducted in Spain, 2 studies were conducted in Croatia, 2 studies were conducted in Brazil, 1 study was conducted in Korea, 1 study was conducted in Switzerland, 1 study was conducted in Thailand, and 1 study was conducted in China. Of these studies, three were multi-center studies $[10,23,24]$ and seven were single-center studies [15-22]. The interventions of PS and T-Piece included in the meta-analysis are outlined in Table 2.

\section{Primary outcome}

A total of 10 RCTs including 3165 patients were included, and the successful extubation rate was about $74.0 \%(1166 / 1592$ in the $\mathrm{T}$-piece group and $1176 / 1573$

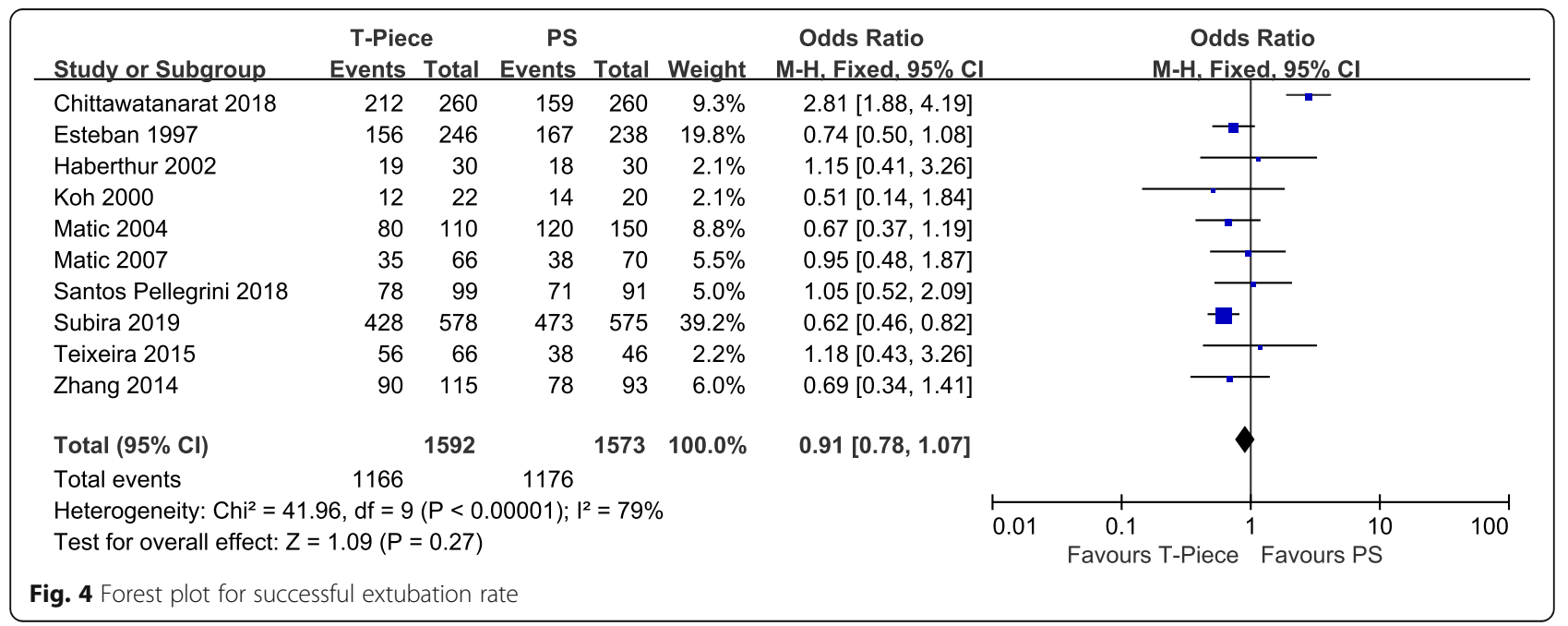




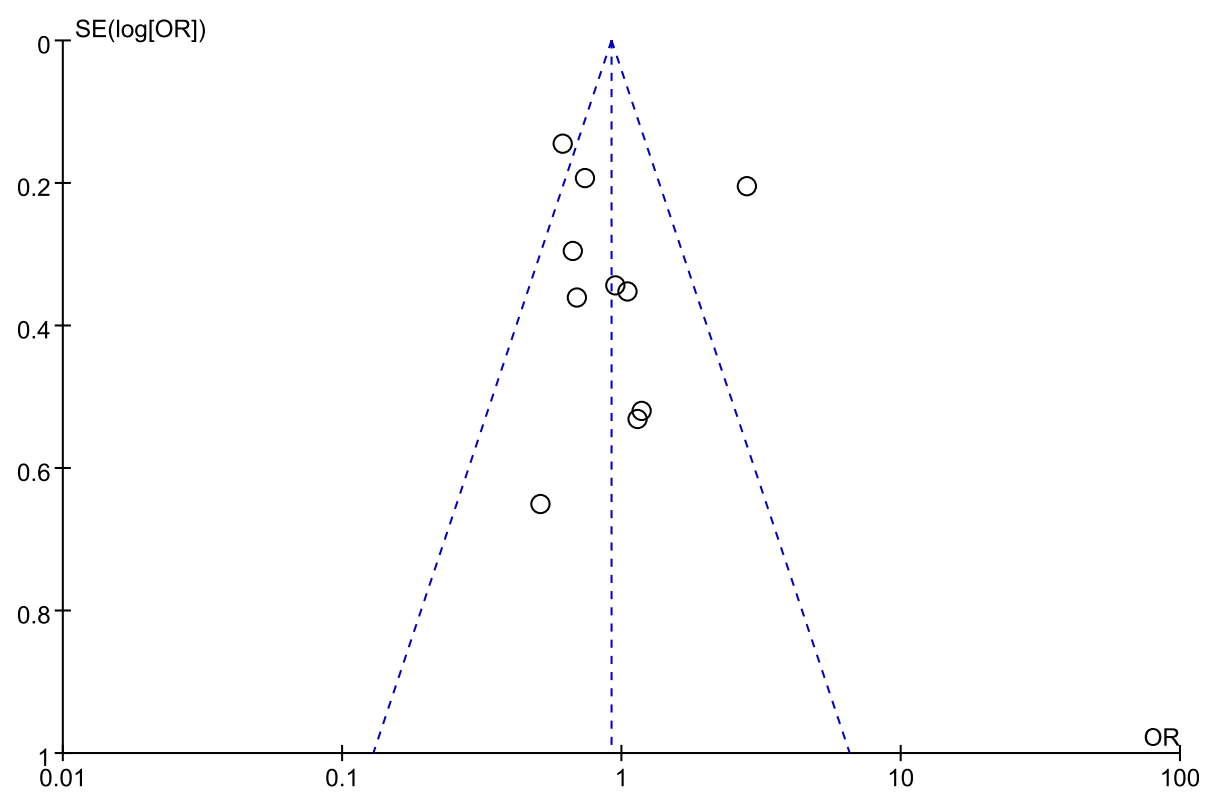

Fig. 5 Funnel plot for successful extubation rate

in the PS group). There was no significant difference of successful extubation rate between $\mathrm{T}$-piece group and PS group using the random effect model (odds ratio $[\mathrm{OR}]=0.91 ; 95 \% \quad \mathrm{CI}, \quad 0.78-1.07 ; \quad P=0.27 ; \quad \mathrm{chi}^{2}=41.96$; $I^{2}=79 \%$ ) (Fig. 4). A funnel plot was used to assess the publication bias (Fig. 5).

\section{Secondary outcomes}

\section{Rate of reintubation}

Five of included studies were analyzed to assess the rate of reintubation. The rate of reintubation was about $14.1 \%$ (171/1205 in the T-piece group and 167/ 1184 in the PS group). There was no statistically significant difference in the rate of reintubation between 2 groups (odds ratio $[\mathrm{OR}]=0.99 ; 95 \% \mathrm{CI}, 0.78-1.26$; $P=0.95 ; \mathrm{chi}^{2}=4.20 ; I^{2}=5 \%$ ) (Fig. 6).

\section{ICU mortality}

Three of the included studies were analyzed to assess the ICU mortality. There was no statistically significant difference in the ICU mortality between 2 groups (odds ratio $[\mathrm{OR}]=1.22 ; 95 \%$ CI, 0.83-1.80; $P=0.30 ; \mathrm{chi}^{2}=1.73 ; I^{2}=$ 0\%) (Fig. 7).

\section{Hospital mortality}

Three of included studies were analyzed to assess the hospital mortality. There was no statistically significant difference in the hospital mortality between 2 groups (odds ratio $[\mathrm{OR}]=1.36 ; 95 \% \mathrm{CI}, 0.99-1.87 ; P=0.06$; $\left.\mathrm{chi}^{2}=2.48 ; I^{2}=19 \%\right)($ Fig. 8).

\section{ICU length of stay}

Four of included studies were analyzed to assess the ICU length of stay. There was no statistically significant

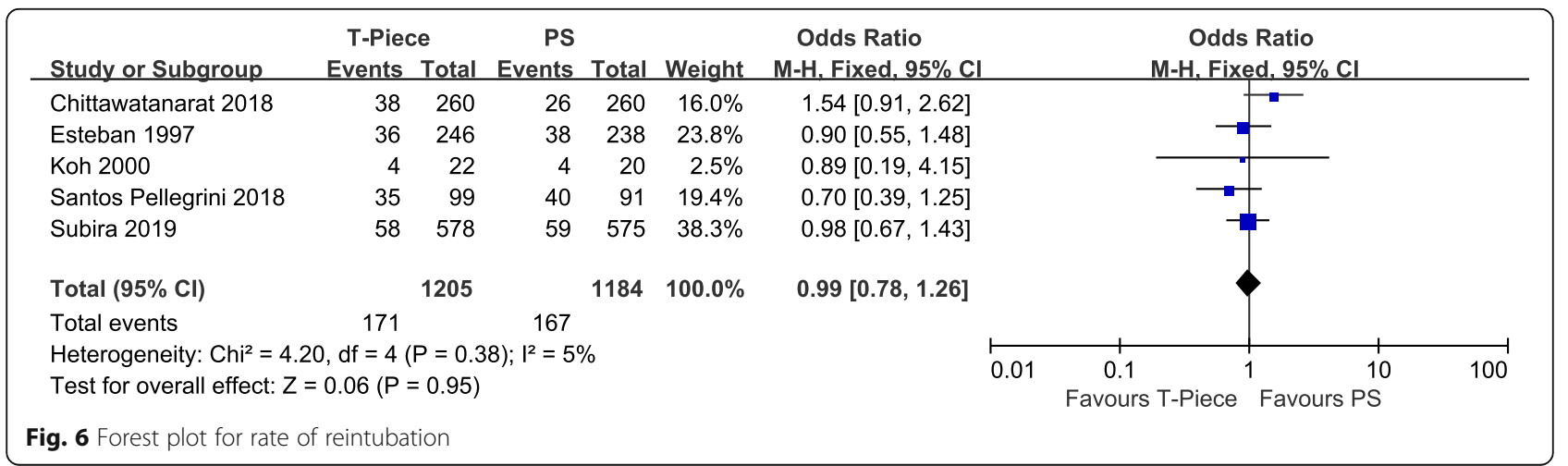




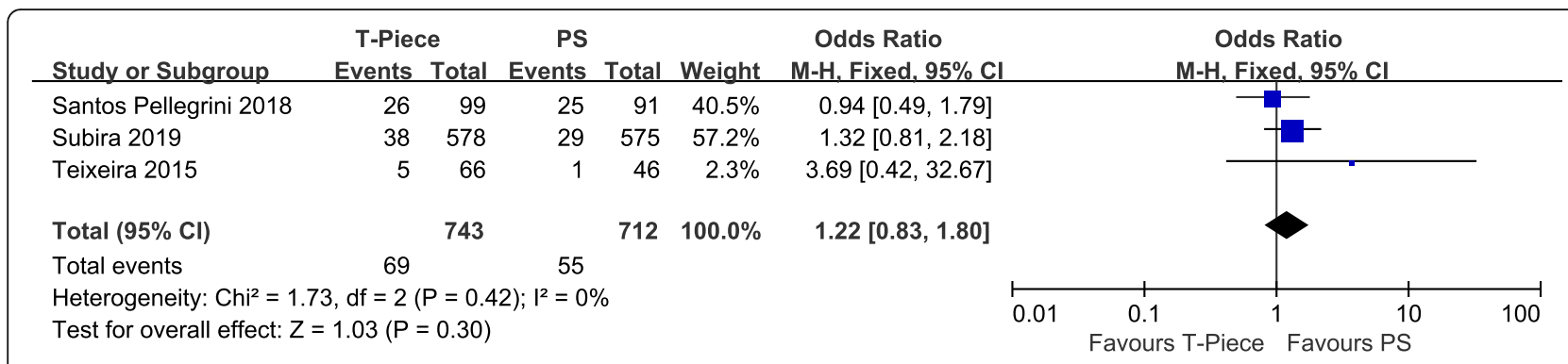

Fig. 7 Forest plot for ICU mortality

difference in the ICU length of stay between 2 groups (Mean difference $=-0.10 ; 95 \% \mathrm{CI},-0.59$ to $0.39 ; P=$ 0.69; $\mathrm{chi}^{2}=3.43 ; I^{2}=13 \%$ ) (Fig. 9).

\section{Hospital length of stay}

Four of included studies were analyzed to assess the hospital length of stay. There was no statistically significant difference in the hospital length of stay between 2 groups (Mean difference $=-0.82 ; 95 \% \mathrm{CI},-2.2$ to 0.55 ; $P=0.24 ; \mathrm{chi}^{2}=0.63 ; I^{2}=0 \%$ ) (Fig. 10).

\section{Discussion}

This systematic review and meta-analysis of ten unique RCTs including 3165 patients compared Tpiece and pressure support ventilation as spontaneous breathing trials in critically ill patients. We found that the overall successful extubation rate was about $74.0 \%$ and there was no significant difference of successful extubation rate between the $\mathrm{T}$-piece group and PS group. Extubation failure may occur because of upper-airway obstruction, ineffective cough, and excessive respiratory secretions that cannot be managed by the patient [2]. Another potential reason for extubation failure is loss of positive pressure in the chest after extubation in subjects weaned to PSV [25]. PSV allows patients to retain control over respiratory rate and timing, inspiratory flow rate, and tidal volume. In addition, physicians can modulate a satisfactory workload for the patients by monitoring breathing frequency and accessory muscle activity during PSV. Because of these potential advantages, the value of PSV as a technique to gradually withdraw ventilator support is generally recognized for patients who have weaning difficulties [17]. Sklar et al. [3] recently pointed out that PSV significantly reduces the work of breathing and pressure-time product compared to the T-piece, which could, in turn, more closely represent the post-extubation scenario. However, noninvasive mechanical ventilation (NIV) dissemination as an adjunctive for extubation makes clinical interpretation of these data difficult [24]. The major finding of our study suggests that both spontaneous breathing using T-piece and PSV are suitable methods for successful extubation of patients with critical illness from mechanical ventilation.

The main goal of a weaning trial is to identify patients who are able to breathe without a ventilator with the minimum risk of extubation failure and its potential complications [26]. Daily screening of respiratory function by SBT is associated with a shorter duration of mechanical ventilation [27]. After a successful SBT and extubation, 10 to $25 \%$ of patients require reintubation, and reintubation is associated with higher mortality [28, 29]. In this meta-analysis, the reintubation rate was not significantly different between the 2 groups (about $14.1 \%$ ), which is lower than the $17 \%$ in the first study by Esteban et al. [16] and similar to the $13 \%$ in their second

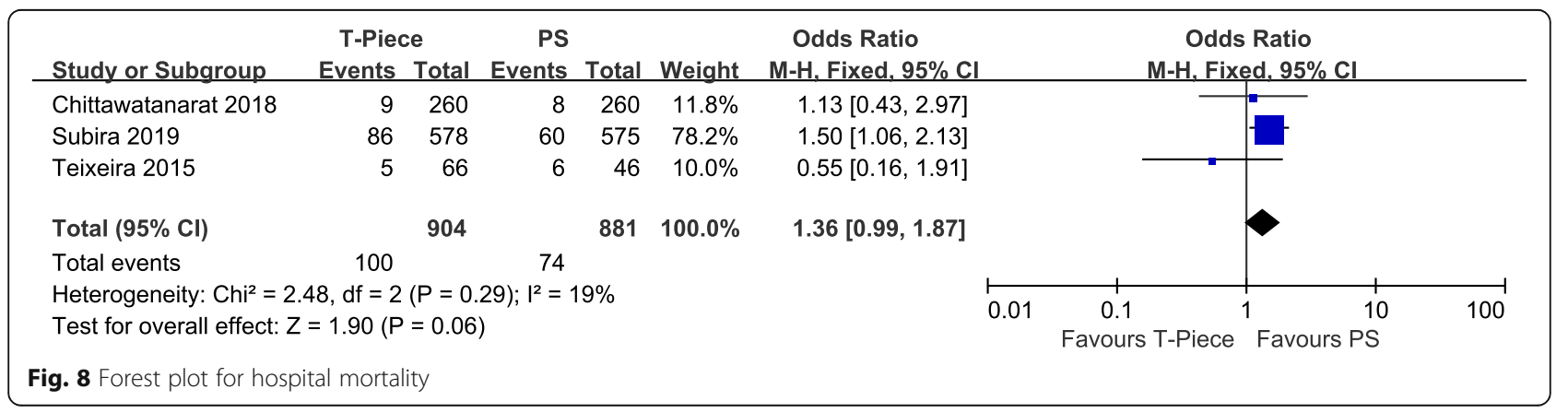




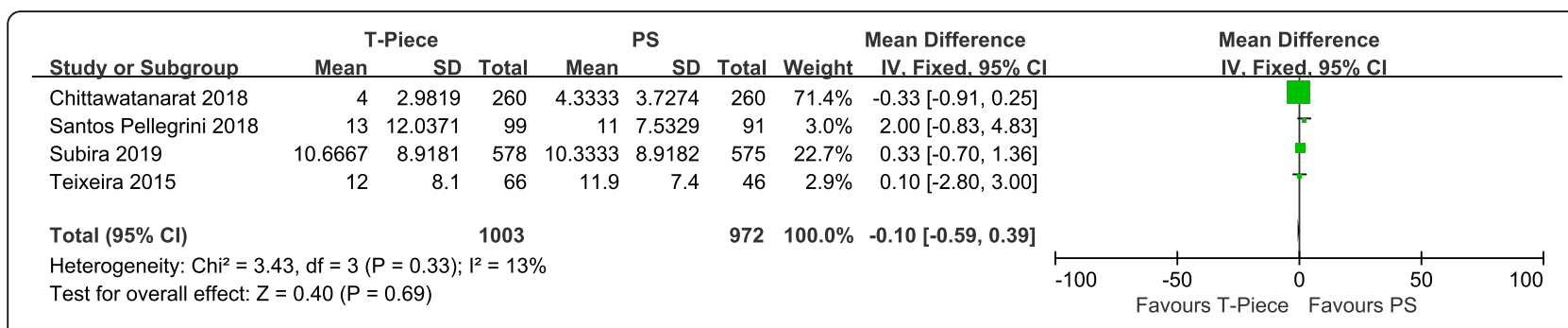

Fig. 9 Forest plot for ICU length of stay

study [30]. Conversely, the reintubation rate was higher than in a study by Perren et al. [31] (9\% for short SBTs and $4 \%$ for long SBTs), but that study has a singlecenter design and the small sample size precludes direct comparison.

Hospital mortality and ICU mortality were not statistically significant different between 2 groups. ICU or hospital mortality may be not directly related to the SBT technique which is the intervention that is applied for a very short period during the course of ICU admission. Patient mortality is associated with prolonged intubation or unsuccessful weaning and they significantly increased medical costs because of extended hospitalization. Besides this, we also found that hospital length of stay and ICU length of stay were not statistically significant different between 2 groups. This finding can be explained by the reintubation rate, APACHE II score at admission, and the overall successful extubation rate, which were not significantly different between the 2 groups.

A variety of workers have indicated that continuous positive airway pressure of $5 \mathrm{~cm} \mathrm{H}_{2} \mathrm{O}$, typically considered as minimal support, decreases patient work of breathing by as much as $40 \%$. Pressure support of 5 $\mathrm{cm} \mathrm{H}_{2} \mathrm{O}$ also decreases patient work of breathing by 30 to $40 \%$ [32, 33]. The vast majority of patients can cope with a 40 to $60 \%$ increase in work of breathing at the point of extubation, but a fragile patient may not [34]. The small population of marginal patients will likely require reintubation. Reintubation is associated with a significant mortality rate. It is necessary to look for the high-risk patient and treat all patients as vulnerable and assess their ability to breathe.
Our meta-analysis has several characteristics: (1) We conducted a systematic search of several databases to identify all RCTs comparing T-piece and PSV SBT techniques in weaning subjects. (2) We employed standardized techniques to assess risk of bias and overall quality of evidence.

This meta-analysis is associated with several limitations. First, the number of included studies is small. Further randomized clinical trials should be conducted in order to assess whether or not PSV is safer and more effective compared to the T-piece method for achieving relevant clinical outcomes among adult patients with at least $24 \mathrm{~h}$ of invasive ventilation. Second, many of the secondary outcomes such as hospital length of stay or hospital mortality were not included in all of the studies examined in this meta-analysis. Third, the rate of SBT success is also very important because successful extubation after passing the SBT will be also related to upper airway patency and adequacy of secretion clearance. Only if the patients have the above conditions can they pass the SBTs. However, not all of included studies showed this data. Fourth, there was substantial heterogeneity among the included studies. Therefore, our findings should be interpreted with caution.

\section{Conclusion}

T-piece and PSV as SBTs are considered to have comparable predictive power of successful extubation in critically ill patients. The analysis of secondary outcomes also shows no significant difference in the rate of reintubation, ICU and hospital length of stay, and ICU and

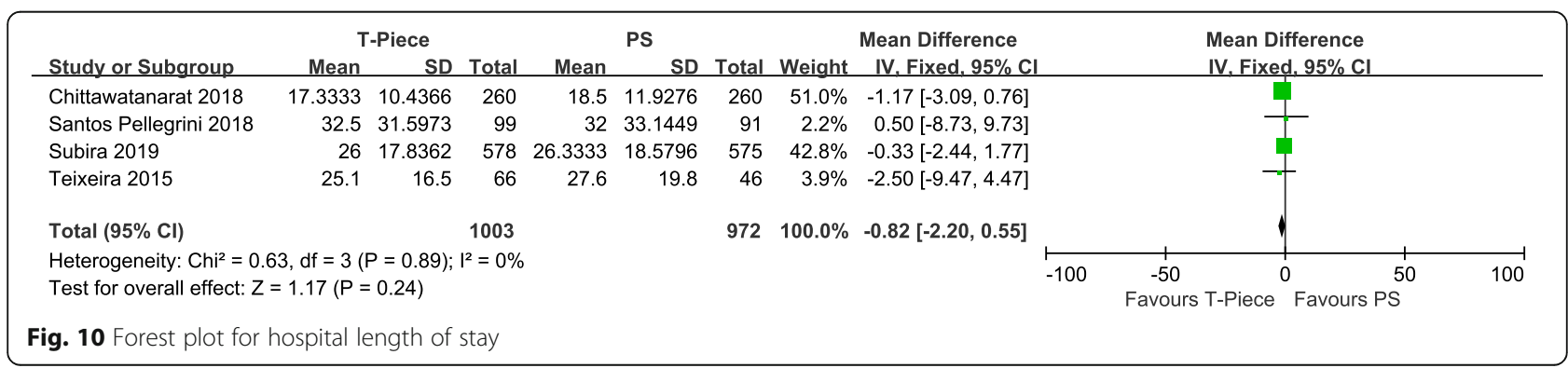


hospital mortality between the 2 groups. Further randomized controlled studies of SBTs are still required.

\section{Abbreviations}

$\mathrm{Cl}$ : Confidence interval; ICU: Intensive care unit; MD: Mean difference; NIV: Noninvasive mechanical ventilation; OR: Risk ratio; PRISMA: Preferred Reporting Items for Systematic Reviews and Meta-Analyses; PSV: Pressure support ventilation; RCTs: Randomized controlled trials; SBT: Spontaneous breathing trial

\section{Acknowledgements}

Not applicable.

\section{Funding}

This work was supported by the Project of Natural Science Foundation of Jilin Province (NO.20160101142JC).

\section{Availability of data and materials}

All data generated or analyzed during this study are included in this published article.

\section{Authors' contributions}

YL searched the scientific literature and drafted the manuscript. HL contributed to the conception and design and data interpretation. HL also helped to collect the data and performed the statistical analyses. DZ contributed to the conception and design, data interpretation, manuscript revision for critical intellectual content, and supervision of the study. All authors read and approved the manuscript.

\section{Ethics approval and consent to participate}

Not applicable.

\section{Consent for publication}

Not applicable.

\section{Competing interests}

The authors declare that they have no competing interests.

\section{Publisher's Note}

Springer Nature remains neutral with regard to jurisdictional claims in published maps and institutional affiliations.

\section{Received: 7 October 2019 Accepted: 7 February 2020}

Published online: 26 February 2020

\section{References}

1. Perren A, Brochard L. Managing the apparent and hidden difficulties of weaning from mechanical ventilation. Intensive Care Med. 2013;39(11): 1885-95.

2. Deab SA, Bellani G. Extubation failure after successful spontaneous breathing trial: prediction is still a challenge! Respir Care. 2014;59(2):301-2.

3. Sklar MC, Burns K, Rittayamai N, Lanys A, Rauseo M, Chen L, Dres M, Chen GQ, Goligher EC, Adhikari NKJ, Brochard, et al. Effort to breathe with various spontaneous breathing trial techniques. A physiologic meta-analysis. Am J Respir Crit Care Med. 2017;195(11):1477-85.

4. Esteban A, Anzueto A, Frutos F, Alía I, Brochard L, Stewart TE, Benito S, Epstein SK, Apezteguía C, Nightingale P, et al. Mechanical Ventilation International Study Group. Characteristics and outcomes in adult patients receiving mechanical ventilation: a 28-day international study. JAMA. 2002 287(3):345-55

5. Peñuelas O, Frutos-Vivar F, Fernández C, Anzueto A, Epstein SK, Apezteguía C, González M, Nin N, Raymondos K, Tomicic V, et al. Characteristics and outcomes of ventilated patients according to time to liberation from mechanical ventilation. Am J Respir Crit Care Med. 2011;184(4):430-7.

6. Esteban A, Ferguson ND, Meade MO, Frutos-Vivar F, Apezteguia C, Brochard L, Raymondos K, Nin N, Hurtado J, Tomicic V, et al. Evolution of mechanical ventilation in response to clinical research. Am J Respir Crit Care Med. 2008; 177(2):170-7.
7. Thille AW, Harrois A, Schortgen F, Brun-Buisson C, Brochard L. Outcomes of extubation failure in medical intensive care unit patients. Crit Care Med. 2011;39(12):2612-8.

8. Burns KEA, Soliman I, Adhikari NKJ, Zwein A, Wong JTY, Gomez-Builes C, Pellegrini JA, Chen L, Rittayamai N, Sklar M, et al. Trials directly comparing alternative spontaneous breathing trial techniques: a systematic review and meta-analysis. Crit Care. 2017;21(1):127.

9. Pellegrini JA, Moraes RB, Maccari JG, de Oliveira RP, Savi A, Ribeiro RA, Burns KE, Teixeira C. Spontaneous breathing trials with T-piece or pressure support ventilation. Respir Care. 2016;61(12):1693-703.

10. Subirà C, Hernández G, Vázquez A, Rodríguez-García R, González-Castro A, García C, Rubio O, Ventura L, López A, de la Torre MC, et al. Effect of pressure support vs T-Piece ventilation strategies during spontaneous breathing trials on successful extubation among patients receiving mechanical ventilation: a randomized clinical trial. JAMA. 2019:321(22):2175-82.

11. Schmidt GA, Girard TD, Kress JP, Morris PE, Ouellette DR, Alhazzani W, Burns SM, Epstein SK, Esteban A, Fan E, et al. Liberation from mechanical ventilation in critically ill adults: executive summary of an official American College of Chest Physicians/American Thoracic Society clinical practice guideline. Chest. 2017;151(1):160-5.

12. Moher D, Liberati A, Tetzlaff J, Altman DG, PRISMA Group. Preferred reporting items for systematic reviews and meta-analyses: the PRISMA statement. Open Med. 2009;3(3):e123-30.

13. Higgins JPT, Sally G. Cochrane Handbook for Systematic Reviews of Interventions, version 5.1.0. 2016. Available at: http://training.cochrane.org/ handbook. Accessed 23 Dec 2016.

14. Biggerstaff BJ, Jackson D. The exact distribution of Cochran's heterogeneity statistic in one-way random effects meta-analysis. Stat Med. 2008;27(29): 6093-110.

15. Wan X, Wang W, Liu J, Tong T. Estimating the sample mean and standard deviation from the sample size, median, range and/or interquartile range. BMC Med Res Methodol. 2014;14:135.

16. Esteban A, Alía I, Gordo F, Fernández R, Solsona JF, Vallverdú I, Macías S, Allegue JM, Blanco J, Carriedo D, et al. Extubation outcome after spontaneous breathing trials with T-tube or pressure support ventilation. The Spanish Lung Failure Collaborative Group. Am J Respir Crit Care Med. 1997;156(2 Pt 1):459-65

17. Koh Y, Hong SB, Lim CM, Lee SD, Kim WS, Kim DS, Kim WD. Effect of an additional 1-hour T-piece trial on weaning outcome at minimal pressure support. J Crit Care. 2000;15(2):41-5.

18. Haberthür C, Mols G, Elsasser S, Bingisser R, Stocker R, Guttmann J. Extubation after breathing trials with automatic tube compensation, T-tube, or pressure support ventilation. Acta Anaesthesiol Scand. 2002;46(8):973-9.

19. Matić I, Majerić-Kogler V. Comparison of pressure support and T-tube weaning from mechanical ventilation: randomized prospective study. Croat Med J. 2004;45(2):162-6.

20. Matić I, Danić D, Majerić-Kogler V, Jurjević M, Mirković I, Mrzljak VN. Chronic obstructive pulmonary disease and weaning of difficult-to-wean patients from mechanical ventilation: randomized prospective study. Croat Med J. 2007:48(1):51-8

21. Zhang B, Qin YZ. Comparison of pressure support ventilation and T-piece in determining rapid shallow breathing index in spontaneous breathing trials. Am J Med Sci. 2014;348(4):300-5.

22. Teixeira SN, Osaku EF, Costa CR, Toccolini BF, Costa NL, Cândia MF, Leite MA, Jorge AC, Duarte PA. Comparison of proportional assist ventilation plus, T-tube ventilation, and pressure support ventilation as spontaneous breathing trials for extubation: a randomized study. Res Care. 2015;60(11):1527-35.

23. Chittawatanarat K, Orrapin S, Jitkaroon K, Mueakwan S, Sroison U. An open label randomized controlled trial to compare low level pressure support and T-piece as strategies for discontinuation of mechanical ventilation in a general surgical intensive care unit. Med Arch. 2018;72(1):51-7.

24. Santos Pellegrini JA, Boniatti MM, Boniatti VC, Zigiotto C, Viana MV, Nede WL, Marques LDS, Dos Santos MC, de Almeida CB, Dal' Pizzol CP, et al, Pressure-support ventilation or T-piece spontaneous breathing trials for patients with chronic obstructive pulmonary disease -A randomized controlled trial. PLoS One. 2018; 13(8):e0202404.

25. Eskandar N, Apostolakos MJ. Weaning from mechanical ventilation. Crit Care Clin. 2007:23(2):263-74.

26. Frutos-Vivar F, Esteban A, Apezteguia C, González M, Arabi Y, Restrepo MI, Gordo F, Santos C, Alhashemi JA, Pérez F, et al. Outcome of reintubated patients after scheduled extubation. J Crit Care. 2011;26(5):502-9. 
27. Ely EW, Baker AM, Dunagan DP, Burke HL, Smith AC, Kelly PT, Johnson MM, Browder RW, Bowton DL, Haponik EF. Effect on the duration of mechanical ventilation of identifying patients capable of breathing spontaneously. $\mathrm{N}$ Engl J Med. 1996;335(25):1864-9.

28. Thille AW, Cortés-Puch I, Esteban A. Weaning from the ventilator and extubation in ICU. Curr Opin Crit Care. 2013;19(1):57-64.

29. Jaber S, Quintard H, Cinotti R, Asehnoune K, Arnal JM, Guitton C, PaugamBurtz C, Abback P, Mekontso Dessap A, Lakhal K, et al. Risk factors and outcomes for airway failure versus non-airway failure in the intensive care unit: a multicenter observational study of 1514 extubation procedures. Crit Care. 2018;22(1):236

30. Esteban A, Alía I, Tobin MJ, Gil A, Gordo F, Vallverdú I, Blanch L, Bonet A, Vázquez A, de Pablo R, et al. Spanish lung failure collaborative group. Effect of spontaneous breathing trial duration on outcome of attempts to discontinue mechanical ventilation. Am J Respir Crit Care Med 1999;159(2): 512-518.

31. Perren A, Domenighetti G, Mauri S, Genini F, Vizzardi N. Protocol-directed weaning from mechanical ventilation: clinical outcome in patients randomized for a 30-min or 120-min trial with pressure support ventilation. Intensive Care Med. 2002;28(8):1058-63.

32. Tobin MJ. Extubation and the myth of "minimal ventilator settings". Am J Respir Crit Care Med. 2012;185(4):349-50.

33. Sassoon CS, Light RW, Lodia R, Sieck GC, Mahutte CK. Pressure-time product during continuous positive airway pressure, pressure support ventilation and T-piece during weaning from mechanical ventilation. Am Rev Respir Dis. 1991;143(3):469-75.

34. Tobin MJ. Physiologic basis of mechanical ventilation. Ann Am Thorac Soc. 2018;15(Suppl 1):S49-52.

Ready to submit your research? Choose BMC and benefit from:

- fast, convenient online submission

- thorough peer review by experienced researchers in your field

- rapid publication on acceptance

- support for research data, including large and complex data types

- gold Open Access which fosters wider collaboration and increased citations

- maximum visibility for your research: over $100 \mathrm{M}$ website views per year

At BMC, research is always in progress.

Learn more biomedcentral.com/submissions 